\section{PRENATAL ORIGINS OF DISEASE IN LATER LIFE AND A FAIR AMOUNT OF CARDIOVASCULAR PUBLIC HEALTH}

In this issue there is a set of papers on various aspects of heart disease, with some cross reference to the origins of adult health in prenatal life and the Barker hypothesis.

A paper from the Netherlands seems to show that twice weekly, rather than weekly gymnastics is needed to obtain full health benefits from this level of physical activity, while there is evidence of the "inverse care law" being alive and well in primary care in Sheffield. Support for a regional approach to the provision of cardiac surgery comes from Italy, where quality and access seem to benefit from a focus at this aggregate level.

See pages $83,89,97$

Meanwhile, Lawlor et al produce more evidence that intra-uterine exposures that affect fetal growth also affect future adult CHD risk. The authors claim that the inverse association between birth weight and CHD may in part be mediated via insulin resistance. And from the same stable comes the suggestion that at least some of the association between the birth weight of individuals and their later risk of diabetes may be genetic and therefore not susceptible to modification by interventions that influence intra-uterine development.

See pages 120,126

On the environmental side, congestive heart failure in Quebec is highest during the winter and declines in the summer, with the suggestion that absolute temperature change may not be as important as thresholds in precipitating decompensation.

See page 129
In this issue we also have:

- Support from Finland for the old chestnut of an inverse relation between water hardness and coronary heart disease.

- Support for the association between low job control and first myocardial infarction, from Lithuania.

- No clear evidence for an association between Kava use and ischaemic heart disease, from a case-control study in Aboriginal communities in Northern Australia.

\section{See pages 136, 131, 140}

Two Glossaries clarify the use of terms relating to the developmental origins of adult health and disease and cardiovascular epidemiology and prevention.

See pages 114, 116

The Gallery this month includes a profile of Vilma Hunt, an influential woman in occupational health who has contributed to our understanding of the health aspects of nuclear radiation; and another scrutiny of the use of disabling words for people with impairments.

See pages 96,82

Other findings this month include:

- Modelling can be used to estimate the potential health impacts of air quality management programmes.

- Skin cancer is less common in people with multiple sclerosis.

- Country of birth plays only a minor part in differences in healthcare expenditure in Malmo.

- Physical and mental unhealthy days may be used as valid summary measures of health status at the country level.

- A flurry of letter writing on various topics from recent issues-the editors find this very encouraging and would invite these debates to continue. Don't forget the rapid response facility on our web site: to submit an "e-Letter" go to the abstract/ full text of the article and click on "Submit a response".

See pages 103, 142, 145, 150, 156

Hygieia highlights:

- The presence of osteoarthritis in Finnish men significantly predicted cardiovascular deaths.

- Stroke incidence and fatality increase with age even in the very old in the Netherlands.

- The impact of musculoskeletal disorder will grow as life expectancy increases, but with enormous variation in total hip replacement rates in different countries at the present time.

- Congenital syphilis returns to the Russian Federation.

- And, the high incidence of gonorrhoea in black Caribbean men in Birmingham, UK is associated with a lesser degree of acculturation, greater number of partners, not being married or using condoms, attending a single sex school, and not holding belief that sex before marriage is wrong.

See page 160 